https://doi.org/10.4314/jpb.v17i1.6

Vol. 17 no. 1, pp. 29-33 (March 2020)

http://ajol.info/index.php/jpb

\section{Journal of \\ PHARMACY AND BIORESOURCES}

\title{
Quality assessment of brands of erythromycin stearate tablets marketed in Abuja, Nigeria
}

\author{
Kudirat B. MUSTAPHA ${ }^{1}$, Marlene D. EKPO ${ }^{2 *}$, Isa H. GALADIMA ${ }^{1}$, Rukaiyatu A. \\ KIRIM $^{1}$, Olubukola A. ODENIRAN ${ }^{1}$, Theophilus A. ACHE ${ }^{1}$ \\ ${ }^{I}$ Department of Medicinal Chemistry and Quality Control, National Institute for Pharmaceutical Research and \\ Development, Idu, Abuja. Nigeria. \\ ${ }^{2}$ Department of Pharmaceutics and Pharmaceutical Technology, University of Uyo, Uyo. Nigeria.
}

Received $4^{\text {th }}$ October 2019; Accepted $31^{\text {st }}$ January 2020

\begin{abstract}
Erythromycin is one of the most frequently prescribed antibiotics. With the increasing number of pharmaceutical industries, the possibility of purchasing a substandard product is on the high side. This makes it necessary to subject various commercially produced brands of erythromycin to quality evaluation in order to ascertain the quality. In this quality assessment study, six (6) brands of erythromycin tablets were subjected to physicochemical assay using standard physical methods and UV/VIS spectrophotometric analysis at $480 \mathrm{~nm}$. The calibration curve for reference erythromycin was linear over a concentration range of $10-100 \mu \mathrm{g} / \mathrm{ml}$ with a correlation coefficient $\left(\mathrm{R}^{2}\right)$ of 0.999 . All the brands had standard deviation of weight greater than \pm 5 for the weight uniformity test. $66.67 \%$ of the brands passed the test for content of active ingredient. $83.33 \%$ of the brands examined passed the hardness test. All the brands failed the friability test because the percentage weight loss are greater than $1 \%$ as specified in the official book.
\end{abstract}

Keywords: Erythromycin stearate; Tablets; Brands; Pharmaceutical Industries

\section{INTRODUCTION}

The upsurge of pharmaceutical industries in Nigeria producing drug generics has created room for the manufacture and circulation of substandard products due to lower scrutiny or inspection of these manufacturers. This inadequacy of drug quality may result from failure of the entire manufacturing process or from the use of substandard raw materials by drug manufacturing industries [1]. The affordability of these generic brands by consumers has also encouraged the existence of these manufacturers [2]. The use of these substandard drugs contributes highly to the problems of treatment failure and increasing resistance to therapy [3]. Post marketing drug surveillance therefore serves as a means of monitoring the quality and interchangeability of these generic medications for their innovator brands. Erythromycin is one of the most frequently prescribed macrolide antibiotics for the treatment of bacterial infections especially those caused by Mycoplasma pneumoniae and Legionella pneumophila [4]. It has also been used in the

\footnotetext{
* Correspondence. E-mail: marlenedavis60@gmail.com Tel: +234-81690399228

ISSN 0189-8442

2020 Published by Faculty of Pharmaceutical Sciences, University of Jos, Nigeria. Under Creative Commons Attribution-NonCommercial 4.0 International License. https://creativecommons.org/licenses/by-nc/4.0/
} 
treatment of urinary tract infections. It works by stopping the growth of bacteria. Challenges associated with the oral administration of erythromycin include acid instability, bitter taste and gastrointestinal disturbances. To overcome these, most tablets are produced as their salt (stearate, ethyl succinate, and propionate) or enteric coated [5].

Literature has revealed different techniques for the analysis of erythromycin, which includes spectrofluorimetry [6], capillary electrophoresis [7], HPLC [8], microbiological method [9] and spectrophotometry [10]. However, many of these methods require costly equipment and tedious experimental procedure. In 2016, Ukoha and Nwanisobi [11] employed charge transfer complexation as a spectrophotometric method in the quantitative determination of erythromycin. The method involves the use of 2,3-dichloro-5,6-dicyano-1,4-benzoquinone (DDQ), a chromogenic agent that gives highly coloured complexes with erythromycin, which can be measured directly in methanol at the appropriate wavelength. This method proved to be simple and sensitive. The spectrophotometric method used in this research project was employed by Ogah and Ogah [12]. The aim of the study was to assess the quality parameters of brands of erythromycin tablets marketed in Abuja, Nigeria.

\section{EXPERIMENTAL}

Materials. UV-Vis spectrophotometer (UVS-2700), Friability test apparatus (Erweka, Germany), Hardness tester (Erweka, Germany), Analytical balance (Shimadzu, Japan), Filter paper (Whatman), Aluminum foil (Landmark original), Masking tape (Chanco-ABRO), Test tubes (Pyrex), Test tube rack, Volumetric flasks (100 mL, $250 \mathrm{~mL}$ ) (Pyrex), Glass funnel, Measuring cylinders (100 mL, $10 \mathrm{~mL})$ (Pyrex), Pipette (1 mL, $5 \mathrm{~mL}, 10 \mathrm{~mL})$,
Porcelain mortar and pestle, Spatula, Acetonitrile, Distilled water, Concentrated Sulphuric acid. All Chemicals used were of analytical grade. Erythromycin stearate reference standard

Sample collection. Six (6) brands of erythromycin stearate tablets coded E1 to E6 were purchased from different registered pharmacy shops in Abuja, Nigeria. All the brands of erythromycin tablets were checked for batch numbers, National Agency for food and Drug Administration and Control (NAFDAC) numbers, manufacturing dates and expiring dates. All the samples analysed were within the shelf life at the time of investigation.

Determination of calibration curve. $1 \mathrm{mg}$ of Erythromycin stearate reference powder was weighed and $1 \mathrm{ml} \mathrm{1:1} \mathrm{mixture} \mathrm{of} \mathrm{acetonitrile} \mathrm{-}$ water was added to the powder to obtain a 1 $\mathrm{mg} / \mathrm{ml}$ solution. The mixture was made up to $5 \mathrm{~mL}$ to obtain $200 \mu \mathrm{g} / \mathrm{ml}$ concentration. To each $1 \mathrm{ml}$ volume of the $200 \mu \mathrm{g} / \mathrm{ml}$ concentrations, $1 \mathrm{ml}$ of concentrated sulphuric acid was added and heated at $50^{\circ} \mathrm{C}$ using a water bath for 30 minutes. Different concentration ranges between $10 \mu \mathrm{g} / \mathrm{ml}$ to 50 $\mu \mathrm{g} / \mathrm{ml}$ were prepared and immediately analyzed using a UV/Vis spectrophotometer at $480 \mathrm{~nm}$ wavelength. A calibration curve was then plotted

Assay of erythromycin tablets. Powdered tablet equivalent to $10 \mathrm{mg}$ of erythromycin was weighed and $10 \mathrm{ml} \mathrm{1:1} \mathrm{mixture} \mathrm{of}$ acetonitrile and water was added to the powder to obtain a $1 \mathrm{mg} / \mathrm{ml}$ solution. The mixture was filtered and $200 \mu \mathrm{g} / \mathrm{ml}$ concentration for each sample was prepared. To each $1 \mathrm{ml}$ volume of the $200 \mu \mathrm{g} / \mathrm{ml}$ concentrations, $1 \mathrm{ml}$ of concentrated sulphuric acid was added and heated at $50^{\circ} \mathrm{C}$ using a water bath for 30 minutes. The mixture was made up to the $10 \mathrm{ml}$ mark with the acetonitrile-water mixture to obtain a 20 $\mu \mathrm{g} / \mathrm{ml}$ working concentration and immediately 
analyzed using a UV/Vis spectrophotometer at $480 \mathrm{~nm}$. The regression equation from the calibration curve obtained was used to calculate the concentration from the absorbance for each brand.

\section{Determination of weight uniformity.} Twenty tablets, selected from each brand of erythromycin, were weighed individually. The average of three weight determinations of each tablet was obtained. The mean and standard deviation were calculated and compared to the permitted variation in the official monograph.

Friability Test. Determination of resistance to abrasion was conducted using the friability test apparatus. Five (5) tablets from each brand of erythromycin were de-dusted and weighed together $\left(\mathrm{W}_{0}\right)$. They were then placed in the drum of the friability test apparatus and rotated at $25 \mathrm{rpm}$ for 4 minutes. The tablets were removed from the chamber, de-dusted and reweighed (W). The percentage weight loss was calculated with the formula:

$$
\% \text { weight loss }=\mathrm{W}_{0}-\mathrm{W} / \mathrm{W}_{0} \times 100
$$

Hardness test. This test was carried out using the manual hardness tester. Five randomly selected tablets from each brand of Erythromycin were used. The tablets were subjected to crushing and the pressure at which each tablet crushed was recorded. The average crushing pressure obtained for each brand was determined.

\section{RESULTS AND DISCUSSION}

The quantification of erythromycin was based on the calibration curve obtained (Figure 1), The regression equation is

$$
\mathrm{Y}=0.01 \mathrm{X}, \mathrm{r}^{2}=.999
$$

Where, $\mathrm{Y}$ is Absorbance and $\mathrm{X}$ is the concentration of the drug.

Form the results obtained (Table1), four $(66.67 \%)$ brands of the erythromycin tablets $\left(E_{2}, E_{3}, E_{4}\right.$ and $\left.E_{6}\right)$ were chemically equivalent to the reference standard as they had percentage active ingredient content between 90 and 100\%. Satisfactory weight uniformity of tablets is dependent upon strict adherence to good manufacturing practice during granulation and compression stages of tablet manufacture. Results obtained from this study suggests deviation from these good practices as all brands evaluated had standard deviations greater than \pm 5 which is the permitted deviation in weight specified by the United States Pharmacopoeia [13]. The sample $E_{3}$ had the greatest deviation $( \pm 23.661)$ (Table 1) and although it passes the test for content of active ingredient, there is still the need to improve upon its manufacturing as well as that of the other brands evaluated. Hardness measures the tablets resistance to deformation. All the brands $(83.33 \%)$ except sample $\mathrm{E}_{2}$ (with crushing strength of $17.4 \mathrm{~kg} / \mathrm{cm}^{2}$ ) had good compression characteristics and will be able to withstand fracture as erosion as they possessed crushing strength ranging from 4 to $10 \mathrm{~kg} / \mathrm{cm}^{2}$. Chipping or fragmentation of tablets as they undergo abrasion in the course of packaging, transportation, handling or storage is an indicator of poor quality. To check this, friability test; which measures a tablets resistance to abrasion was carried out.

Table 1: Percentage content of the brands of erythromycin tablets

\begin{tabular}{cccccc}
\hline S/N & Brand code & Average Wt. of tablet $(\mathrm{mg})$ & Concentration $(\mu \mathrm{g} / \mathrm{ml})$ & \% Content & Comment \\
\hline 1 & $\mathrm{E}_{1}$ & $918.29 \pm 7.266$ & 17.941 & 89.71 & Fail \\
2 & $\mathrm{E}_{2}$ & $855.76 \pm 11.731$ & 21.960 & 109.8 & Pass \\
3 & $\mathrm{E}_{3}$ & $904.59 \pm 23.661$ & 21.078 & 105.39 & Pass \\
4 & $\mathrm{E}_{4}$ & $887.33 \pm 8.888$ & 19.118 & 95.59 & Pass \\
5 & $\mathrm{E}_{5}$ & $837.79 \pm 10.792$ & 16.372 & 81.86 & Fail \\
6 & $\mathrm{E}_{6}$ & $935.19 \pm 6.076$ & 20.196 & 100.98 & Pass \\
\hline
\end{tabular}


Table 2: Physical properties of erythromycin tablets

\begin{tabular}{lccl}
\hline $\mathrm{S} / \mathrm{N}$ & Brand Code & Hardness $\left(\mathrm{Kg} / \mathrm{cm}^{2}\right)$ & Friability \% \\
\hline 1. & $\mathrm{E}_{1}$ & $8.1 \pm 0.89$ & $2.13 \%$ \\
2. & $\mathrm{E}_{2}$ & $17.4 \pm 0.55$ & $2.33 \%$ \\
3. & $\mathrm{E}_{3}$ & $9.4 \pm 1.82$ & $2.17 \%$ \\
4. & $\mathrm{E}_{4}$ & $7.9 \pm 1.52$ & $2.17 \%$ \\
5. & $\mathrm{E}_{5}$ & $9.8 \pm 0.91$ & $2.38 \%$ \\
6. & $\mathrm{E}_{6}$ & $9.2 \pm 2.08$ & $2.44 \%$ \\
\hline
\end{tabular}

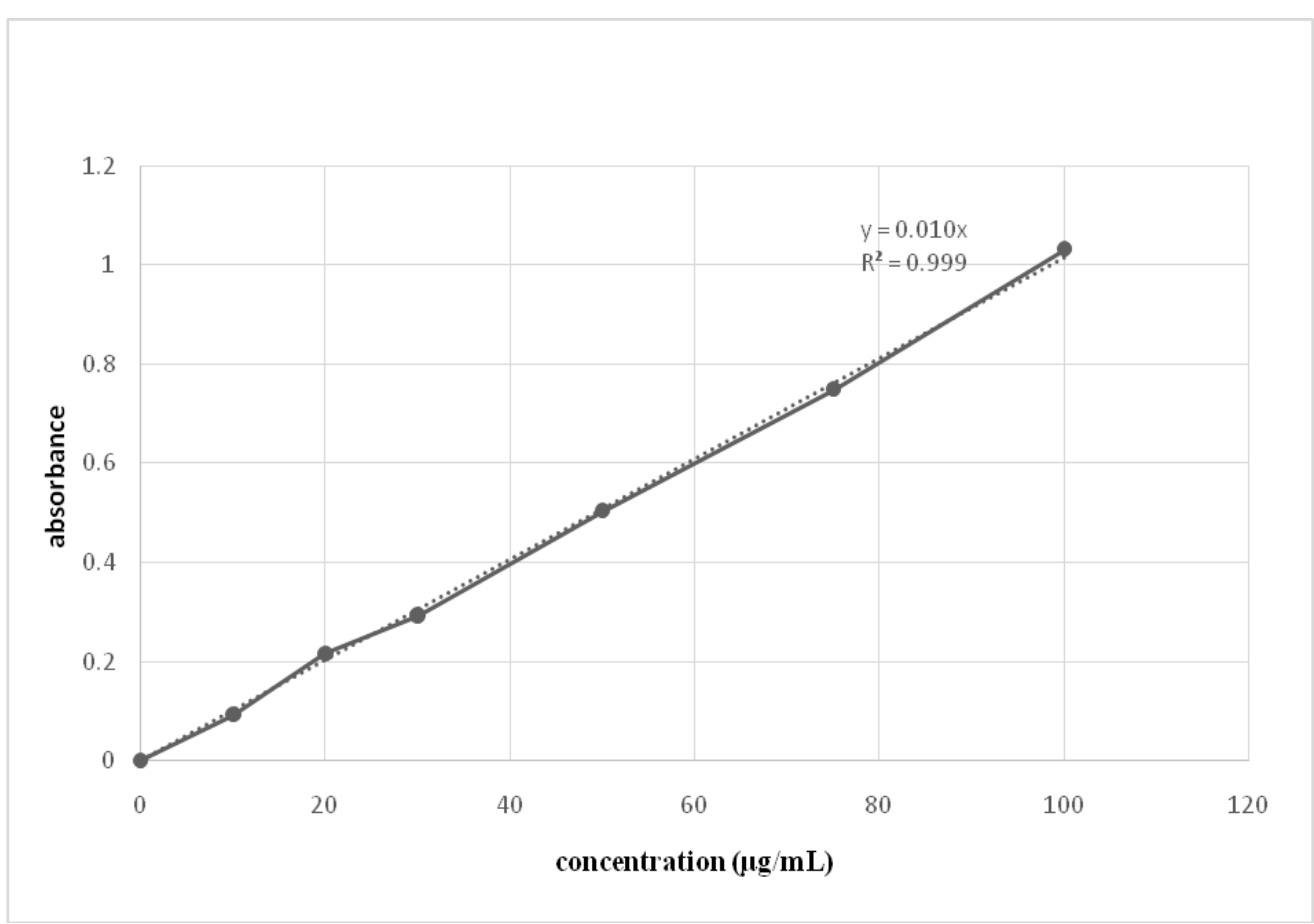

Figure 1: Calibration curve for erythromycin standard

The percentage weight losses obtained ranged between 2.13 and $2.44 \%$, which are above the $1 \%$ limit specified in the British Pharmacopoeia [14]. This implies high susceptibility of the tablets to chipping which could account for the variation in weight obtained for each brand assayed.

Conclusion. In general, the study shows that there is prevalence of sub-standard drug product circulating in the market. Hence, the quality, safety and efficacy of essential drugs in the market should be monitored continuously through post marketing surveillance practices.

\section{REFERENCES}

1. Johnston A. and Holt D. W. (2014). Substandard drugs: a potential crisis for public health. Br. $J$. Clin Pharmacol.78: 218-243.

2. Osadedbe P. O., Uzor P. F., Enwereji P. O. (2011). Quality control and interchangeability of multisourced lisinopril tablets marketed in Nigeria. African Journal of Pharmaceutical Research and Development. 3: 71-76

3. Newton P. N., Green M. D., and Fernández F. M. (2010). Impact of poor-quality medicines in the 'developing' world. Trends Pharmacol Sci. 31: 99-101.

4. Eckman M. and Labus D. (2003). (Eds). Clinical Pharmacology Made Incredibly Easy, $3^{\text {rd }}$ edition, Lippincott Williams and Wilkins, Philadelphia. 
5. Terespolsky S. A., (1992). A Study of the Biopharmaceutics and Pharmacokinetics of the Macrolide Antibiotic, Erythromycin, MSc Thesis Rhodes University USA

6. Pakinaz Y. (2002). Journal of Pharmaceutical and Biomedical Analysis, 27:923-932.

7. Flurer C. (1996). Analysis of Macrolide Antibiotics by Capillary Electrophoresis, 17: 359366

8. Hedenmo M., Eriksson B., (1995). Journal of Chromatography. 692:161-166

9. Bernabaeu J., Camacho M., Gilalegre M., Ruz V. (1999). Journal of Pharmaceutical and Biomedical Analysis 21:347-353.

10. Walash M., Sharaf E., Metwallis M. and Redashabana M. (2004). Arch pharmacy Res. 27:720,729
11. Ukoha O and Nwanisobi C. G. (2016). Spectrophotometric determination of erythromycin using charge transfer complexation. Der Pharma Chemica. 8:59-66.

12. Ogah C. O., and Ogah C.A. (2016). Comparative In vitro Studies of Erythromycin Stearate Tablets Commercially Available in Lagos State, Nigeria International Journal of Research in Pharmacy and Biosciences. 3:7-13.

13. USP (United States Pharmacopoeia) (2014). National Formulary USP 37 NF 32. The United States Pharmacopeial Convention 12601 Twinbrook Parkway, Rockville, Vol.1, MD, USA. 20852. Pg.2850,1145-1146.

14. British Pharmacopeia (2016). Erythromycin Stearate. Vol I, pg 878- 880 